\title{
Characterization of Supermagnetic Cobalt Ferrite Submicrometer Particles Fabricated Under Y-Irradiation
}

\author{
Gracien Bakambo Ekoko, Pierre Osomba Lohohola, Jérémie Lunguya Muswema, \\ Hercule Mulenda Kalele, Omer Muamba Mvele, Joseph Kanza-Kanza Lobo, \\ Désiré Kabuya Tshibangu*
}

Department of Chemistry, University of Kinshasa, Kinshasa, Democratic Republic of the Congo

Email address:

desire.tshibangu@gmail.com (D. K. Tshibangu)

${ }^{*}$ Corresponding author

\section{To cite this article:}

Gracien Bakambo Ekoko, Pierre Osomba Lohohola, Jérémie Lunguya Muswema, Hercule Mulenda Kalele, Omer Muamba Mvele, Joseph Kanza-Kanza Lobo, Désiré Kabuya Tshibangu. Characterization of Supermagnetic Cobalt Ferrite Submicrometer Particles Fabricated Under $\gamma$-Irradiation. Advances in Materials. Vol. 10, No. 1, 2021, pp. 5-11. doi: 10.11648/j.am.20211001.12

Received: April 5, 2021; Accepted: May 14, 2021; Published: June 7, 2021

\begin{abstract}
Magnetic cobalt ferrite has wide spread applications, especially as catalyst for the conversion of alkenes to related aldehydes. Despite several studies found in the literature concerning the fabrication of cobalt ferrite, none has reported on gamma irradiation as a tool for the synthesis of submicrometer sized inverse spinel $\mathrm{CoFe}_{2} \mathrm{O}_{4}$. The actual investigation reports on the application of $\gamma$-irradiation method for the synthesis of superparamagnetic $\mathrm{CoFe}_{2} \mathrm{O}_{4}$, using metal salts precursors and organic reagents. The material fabrication occurs in two main steps as sofar described. The obtained powder was isolated after irradiation and was characterized using X-ray diffraction method, transmission electron microscopy, FT-IR spectroscopy, Raman spectroscopy, UV-visible measurements and vibrating sample magnetometer. Furthermore, the X-ray diffraction data revealed the presence of a reverse spinel structure. The magnetic properties of the fabricated powder exhibited the measured lower coercivity and remanence, demonstrating that the spinel powders are made of superparamagnetic particles and finally, to gain information about the photocatalytic properties of the synthetized material, the room temperature recorded optical measurements for different samples proved that these powder materials may probably exhibit new opportunities which could improve their high photocatalytic efficiency under visible light. The prepared materials could be used as potetentiel candididates for the oxidation of organics compounds.
\end{abstract}

Keywords: Cobalt Ferrite, Supermagnetic, Nanoparticles, $\gamma$-irradiation

\section{Introduction}

Recently nanoscience and technology is exponentially improving owing to their potential applications. Nano-sized materials made of cobalt ferrite $\left(\mathrm{CoFe}_{2} \mathrm{O}_{4}\right)$ could be used both from fundamental research and for various physical, chemical and biological applications. They are used for their thermal, mechanical and chemical stability [1], magnetism and electronics properties [2], sensor design [3], catalysis [4 -7], and medicine [8-9].

The ferrites spinel has a cubic close-packed structure consisting of oxygen arrangement, in which cations with small radius value less than $1 \AA\left(\mathrm{M}^{2+}\right)$ occupies tetrahedral and octahedral sites. This structure is represented by $\mathrm{M}^{2+} \mathrm{O}$.
$\mathrm{Fe}^{3+}{ }_{2} \mathrm{O}_{3}$. A normal spinel structure is obtained in the presence of metal ion $\left(\mathrm{M}^{2+}=\mathrm{Zn}^{2+}, \mathrm{Cd}^{2+}, \mathrm{Mn}^{2+}\right)$, which occupies a tetrahedral site while occupation of octahedral sites with divalent of metal ion $\left(\mathrm{M}^{2+}=\mathrm{Fe}^{2+}, \mathrm{Co}^{2+}, \mathrm{Ni}^{2+}, \mathrm{Cu}^{2+}\right)$ results in an inverse spinel structure.

The potential applications of cobalt ferrite needs to gain a fine control of the morphology and the size of the fabricated material. There is a need to find preparative methods, which allow the sythesis of microstructural materials with specific composition and morphology by controlling physicochemical parameters.

Several methods such as hydrothermal synthesis [10], solgel method [11], coprecipitation [12, 13], thermal decomposition [14], reverse micelle synthesis [15], microemulsion [16], have been reported in the synthesis of 
$\mathrm{CoFe}_{2} \mathrm{O}_{4}$ spinel. All these methods are highly energyconsuming and do not allow a control over the reaction pathways often resulting to agglomerated nanoparticles.

As a piece of information, the irradiation of pure water under $\gamma$-ray leads to the formation of different species such as: ${ }^{\bullet} \mathrm{HO}_{2}, \mathrm{O}_{2}$ and ${ }^{\bullet} \mathrm{O}_{2}{ }^{-}$and eventually the stable products $\mathrm{H}_{2}$, $\mathrm{O}_{2}$ and $\mathrm{H}_{2} \mathrm{O}_{2}$. The concentrations of the radiolysis products depend on radiation energy absorption rate, the solution $\mathrm{pH}$, and temperature, where $\left({ }^{\bullet} \mathrm{OH}, \mathrm{H}_{2} \mathrm{O}_{2}\right.$ and $\left.\mathrm{O}_{2}\right)\left({ }^{\bullet} \mathrm{H}, \mathrm{e}^{-}\right.$aq and ${ }^{-} \mathrm{O}_{2}{ }^{-}$) are respectively the oxidizing and reducing species, which can readily interact with dissolved transition metal ions $\left(\mathrm{M}^{\mathrm{n}+}\right)$ to change their oxidation states. The condensation and the formation of oxide particles are due to the conversion of dissolved metal species to oxidation states with low solubility. However, to avoid the particles agglomeration the use of an appropriated surfactants is necessary $[17,18]$.

The fabrication at room temperatures in an aqueous environment under gamma irradiation of nanoparticles made of metal oxides offers some benefits over the conventional methods. The gamma irradiation does not required toxic or hard reagents, and does not necessitating complex purification steps and is able of controlling the particle size and structure. The size of nanoparticles depends of the choice of solvents and stabilizer, the $\mathrm{pH}$ during synthesis, and absorbed dose.

We recently reported on $\gamma$-irradiation technique as a tool in preparing $\mathrm{Fe}_{2} \mathrm{O}_{3}$ nano-particles [19-21], zinc sulfide nanocrystalline in a non-aqueous system [22], spherically nanocrystalline sized $\mathrm{Co}_{3} \mathrm{O}_{4}$ in alkaline medium [23] and on the preparation of non- stoichiometric $\mathrm{NiO}$ nanocrystalline [24] et silver nanodispesed metal [25].

The objective of the present investigation is to report on $\gamma$ irradiation as a facile route to prepare the submicrometer sized particles made of cobalt ferrite, which have been prepared at room temperature and ambient pressure. The fabricated material was characterized to find out about its chemical composition, structure, optical and magnetic properties.

\section{Experimental Procedure}

\subsection{Sample Preparation}

The reagents used in the present investigation for the preparation of the spinel made of $\mathrm{CoFe}_{2} \mathrm{O}_{4}$ were of highpurity analytical grade and were used as received: cobalt (II) chloride hexahydrate, $\left[\mathrm{CoCl}_{2} \cdot 6 \mathrm{H}_{2} \mathrm{O}\right]$ as $\mathrm{Co}^{2+}$ precursor, iron (III) sulphate $\left[\mathrm{Fe}_{2}\left(\mathrm{SO}_{4}\right)_{3}\right]$ as $\mathrm{Fe}^{3+}$ source, distilled water, isopropyl alcohol, $\left[\left(\mathrm{CH}_{3}\right)_{2} \mathrm{CHOH}\right]$, anhydrous sodium hydroxide, $[\mathrm{NaOH}]$, polyvinyl alcohol [PVA] and ammonium buffers.

The starting solutions made of inorganic precursor containing both iron (III) and cobalt (II) were prepared by mixing an appropriated amount distilled water and the all were stirred till to obtain a lucid solution.

The procedure for preparing cobalt ferrite composite includes two steps (refer to Table 1):

(i) The preparation of the sols constituted of a mixture of coprecipitated $\mathrm{Fe}^{3+}$ and $\mathrm{Co}^{2+}$ ions. The sols of different composition were made by slowly dropping an appropriate amount of high purity pellets of sodium hydroxide into the solutions. Mixed solutions were stirred continuously for $20 \mathrm{~min}$ at room temperature until sols were formed. A me seared volume of isopropyl alcohol (with a concentration of about $3.0 \mathrm{~mol}$ /L) was employed in order to scavenger the oxidative radicals $\left(H O^{\bullet}\right.$ ) produced during water radiolysis. A specific amount of organic surfactant, Polyvinyl alcohol (PVA $0.1 \mathrm{~mol} / \mathrm{L}$ ) was added in the solution in order to stabilize growth of particles during the spinel preparation. Anhydrous $\mathrm{NaOH}$ pellets were added in to the final solutions in order to obtain a mixture of metallic hydroxides in alkaline medium of $\mathrm{pH} 10.5$ under continuous stirring. Finally, to avoid the irreversible precipitation of parasitic cobalt salts, ammoniacal buffer was added into the final solutions.

(ii) the transformation of the sols, made of different compositions of $\mathrm{FeOOH}$ and $\mathrm{Co}(\mathrm{OH})_{2}$ under $\gamma$ irradiation in the field of ${ }^{60} \mathrm{Co} \gamma$-source of $325,000 \mathrm{Ci}$ with variable absorbed doses $\left(0.25 \mathrm{kGy} \mathrm{h}^{-1}\right)$.

The particles were precipitated and isolated by centrifugation after irradiation. To remove the by-products, these particles were washed several times with distilled water, absolute alcohol, and acetone, and finally they were dried in electric oven at $60^{\circ} \mathrm{C}$ for six hours. The black product constituted of pure cobalt ferrite was obtained and characterized. The preparation of the solutions of $\mathrm{Fe}_{2} \mathrm{CoO}_{4}$ is detailed in Table 1.

Table 1. Preparation of cobalt iron oxide, $\mathrm{CoFe}_{2} \mathrm{O}_{4}$

\begin{tabular}{|c|c|c|c|c|c|c|c|c|}
\hline $\begin{array}{l}\text { Sample } \\
\text { number }\end{array}$ & $\begin{array}{l}{\left[\mathrm{Co}^{2+}\right]} \\
\mathrm{mol} \mathrm{L}^{-1}\end{array}$ & $\begin{array}{l}{\left[\mathrm{Fe}^{3+}\right]} \\
\mathrm{mol} \mathrm{L}^{-1}\end{array}$ & $\begin{array}{l}{[I P A]} \\
\text { mol L }^{-1}\end{array}$ & $\begin{array}{l}{[P V A]} \\
\text { mol L }^{-1}\end{array}$ & $\begin{array}{l}{[\mathrm{NaOH}]} \\
\mathrm{mol} \mathrm{L}^{-1}\end{array}$ & $\begin{array}{l}{\left[\mathrm{NH}_{3} \cdot \mathrm{H}_{2} \mathrm{O}\right]} \\
\mathrm{mol} \mathrm{L}^{-1}\end{array}$ & $\begin{array}{l}{\left[\left(\mathrm{NH}_{4}\right)_{2} \cdot \mathrm{SO}_{4}\right]} \\
\mathrm{mol} \mathrm{L}^{-1}\end{array}$ & Irrad. dose (kGy) \\
\hline 1 & 0.04 & 0.08 & 3.0 & 0.1 & 1.0 & 0.4 & 0.1 & 43 \\
\hline 2 & 0.04 & 0.08 & 3.0 & 0.1 & 1.0 & 0.4 & 0.1 & 11 \\
\hline 3 & 0.08 & 0.08 & 3.0 & 0.1 & 1.0 & 0.4 & 0.1 & 30 \\
\hline 4 & 0.08 & 0.08 & 3.0 & 0.1 & 1.0 & 0.4 & 0.1 & 11 \\
\hline 5 & 0.04 & 0.08 & 3.0 & 0.1 & 1.0 & 0.4 & 0.1 & 30 \\
\hline
\end{tabular}

\subsection{Techniques of Characterization}

The prepared powders products (before and after $\gamma$ - irradiation) were identified by X-ray powder diffraction (XRD) patterns, employing a D/MAX-2550 X-ray diffractometer with $\mathrm{Cu}-\mathrm{K} \alpha$ radiation $(\lambda=1.54056 \AA$ ) with a 
nickel filter (Rigaku Co., Japan). The identification of the characteristic functional groups in the synthesized material was made using a FT-IR spectrophotometer (SHIMADZU model). A field emission scanning electron microscopy (FESEM; JEOL JSM-6700F) well equipped with an energy dispersive X-ray (EDAX) spectrophotometer was used to find out about the surface morphology, the size of particles and the elemental compositions of prepared powder. The morphology and the particles size were determined by transmission electron microscopy with an accelerating voltage of $200 \mathrm{kV}$. Magnetic measurements were made at room temperature using a vibrating sample magnetometer. The sample material was performed through Raman measurements, which were carried out at room temperature to find out about the compositional and the structure of the fabricated material.

\section{Results and Discussion}

\subsection{XRD Studies}

The X-ray diffraction technique (diffractograms recorded in the $2 \theta$ range from 15 to $80^{\circ}$ ) was used to identify the phase composition of the fabricated power and the patterns from samples 1 and 5 were similar ( refer respectively to Figure 1(a) and 1(b)). The crystalline nature of the prepared products is proven via the sharpness of diffractogram peaks. For sample 3 (The XRD pattern not shown here), a little amount of $\mathrm{CoO}$ could be identified as a secondary phase and at low irradiation dose (about $11 \mathrm{kGy}$ ), the Xray spectrum (not shown) mainly indicated the presence of cobalt ferrite and certain unidentified phases peaks.

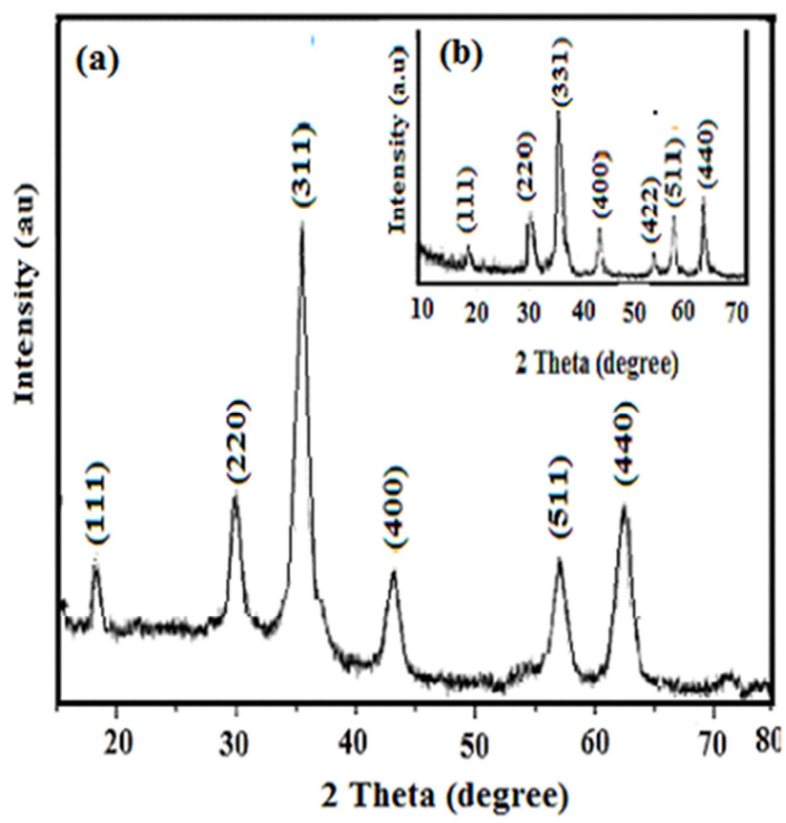

Figure 1. $\mathrm{X}$-ray diffraction patterns of $\mathrm{CoFe}_{2} \mathrm{O}_{4}$ (sample 1), and the insert shows the sample 5 pattern.

All observed peaks were indexed to the pure face centered cubic $\mathrm{CoFe}_{2} \mathrm{O}_{4}$ with inverse spinel structure (JCPDS N $\mathrm{N}^{\circ} 22$ -
1086) [26-28]. No other phases (or impurities) were observed, indicating the purity of the fabricated product. The location of these peaks matched well with the structure of an inverse spinel $\left(\mathrm{TR}_{2} \mathrm{O}_{4}\right)$, where $\mathrm{T}$ is the tetrahedral site and $\mathrm{R}$ the octahedral site. In the spinel, the full $\mathrm{Co}^{2+}$ ions and one half of $\mathrm{Fe}^{3+}$ ions are located in the octahedral site, while the other half of $\mathrm{Fe}^{3+}$ ions are located in the octahedral sites.

\subsection{TEM Images}

The TEM images of the fabricated spinel made of $\mathrm{CoFe}_{2} \mathrm{O}_{4}$ are exhibited in Figure 2. One can observe that the irradiation dose plays an important role in the morphology of the prepared spinels. From Figure $2(b, c)$, one can observed that the sample is mainly consisted of snowball-spindle micrometer particles morphology. Some mesoporous structures were observed and could enhance the photocatalytic performance of the fabricated material. The particle get bigger when the absorbed dose increases.

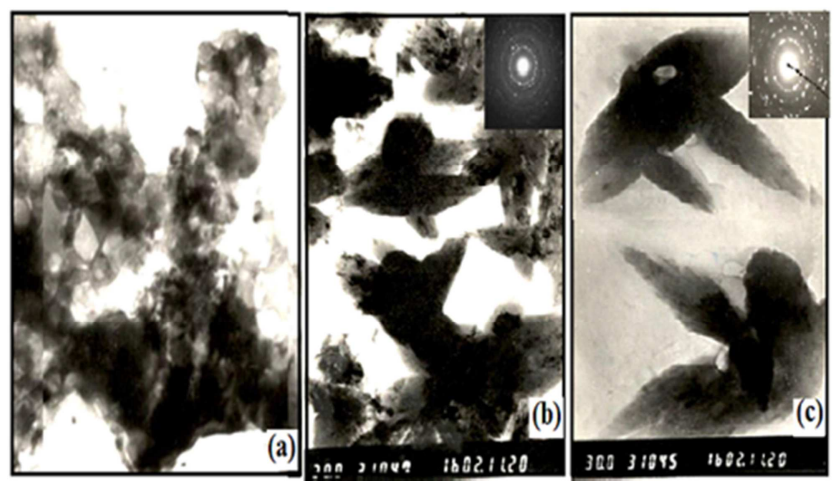

Figure 2. TEM micrographs (with insert, the selected area electron diffraction) of: (a) sols made of coprecipitated $\mathrm{Fe}^{3+}$ and $\mathrm{Co}^{2+}$ ions $(\mathrm{pH}=12)$ before Y-irradiation; (b) Sample 5 of $\mathrm{CoFe}_{2} \mathrm{O}_{4}(30 \mathrm{kGy})$; (c) Sample 1 of $\mathrm{CoFe}_{2} \mathrm{O}_{4}(43 \mathrm{kGy})$.

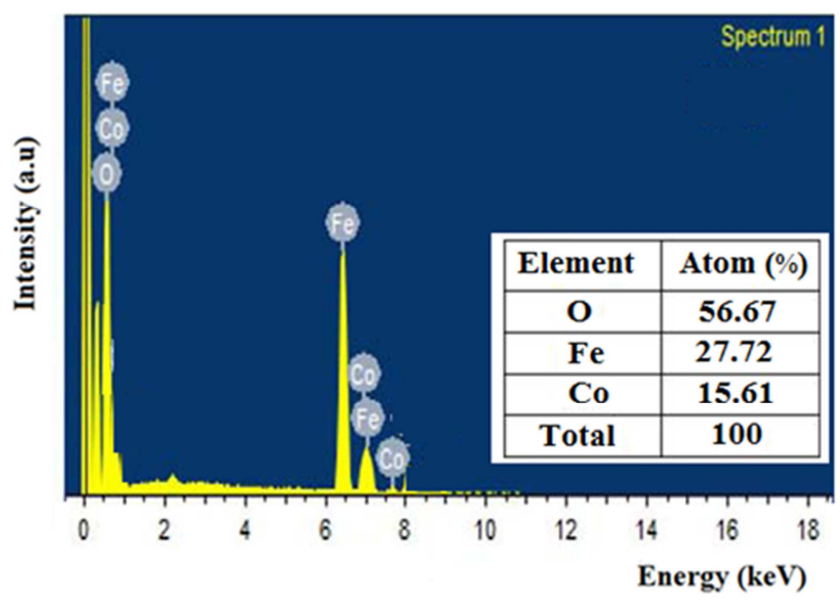

Figure 3. EDS spectrum of prepared $\mathrm{CoFe}_{2} \mathrm{O}_{4}$ (sample 5).

\subsection{Energy Dispersive Studies (EDS)}

The EDS analysis of the prepared sample $1 \mathrm{CoFe}_{2} \mathrm{O}_{4}$ sample as presented in the spectrum of Figure 3. Based on the energies appeared in the presented spectrum, it can be concluded that the mainly chemical composition of the 
prepared powder was very close to the planned one. The spectrum shows the presence of $\mathrm{Co}, \mathrm{Fe}$, and $\mathrm{O}$ elements. The experimental atomic percentages of $\mathrm{Co}, \mathrm{O}$ and $\mathrm{Fe}$ are found to be $15.61 \%, 56.67 \%$, and $27.72 \%$ respectively. The EDS spectrum showed strong signals of cobalt and iron in fabricated sample. No additional peaks were observed, which confirmed that the cobalt ferrite synthesized by $\gamma$-ray irradiation was pure. The EDS spectrum supports others characterization techniques. The calculated atomic ratio of Co: Fe: $\mathrm{O}$ is consistent with the real composition of cobalt ferrite.

\subsection{Analysis by FT- IR Spectroscopy}

In order to ascertain the purity and nature of metal the prepared spinels, the FT- IR spectroscopy investigation was carried out in the region from 4000 to $400 \mathrm{~cm}^{-1}$. The recorded information is shown in Figure 4.

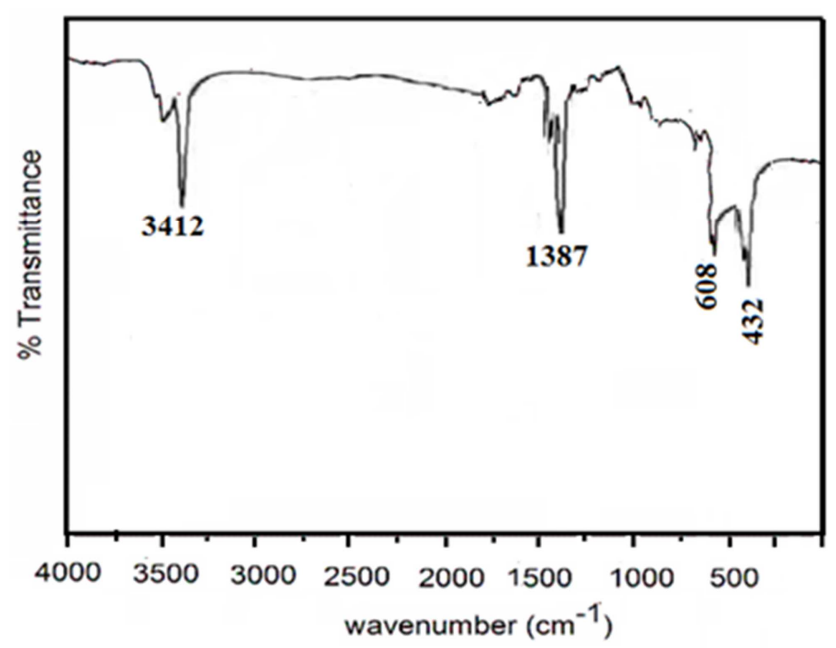

Figure4. The FT-infra red spectra of the fabricated $\mathrm{CoFe}_{2} \mathrm{O}_{4}$ (sample 5).

The band located at $3412 \mathrm{~cm}^{-1}$ is attributed to $\mathrm{OH}$ stretching of the capping agent, polyvinyl alcohol used for the preparation of $\mathrm{CoFe}_{2} \mathrm{O}_{4}$ spinel. The positioned band at $1387 \mathrm{~cm}^{-1}$ can be assigned to the binding vibrations of water molecules absorbed on the synthesized $\mathrm{CoFe}_{2} \mathrm{O}_{4}$ surface. The peaks positioned at 608 and $432 \mathrm{~cm}^{-1}$ are due to stretching vibration of Metal-Oxygen bond in octahedral and tetrahedral sites [29, 30]. The observed absorption band located at 432 $\mathrm{cm}^{-1}$ could be associated to the tetrahedral cation $\left(\mathrm{Fe}^{3+}-\mathrm{O}^{2-}\right.$, in $\alpha-\mathrm{Fe}_{2} \mathrm{O}_{3}$ ) vibration mode of prepared submicrometer spinel particles [31, 32].

\subsection{Raman Phonon Modes Analysis}

To gain information about the vibrational energy states within the synthetized sample, we used Raman spectroscopy. Measurements were made at room temperature (Figure 5). From, this figure, one can clearly see that all the peaks characteristic of cobalt spinel ferrites appear in the spectra, which confirms the formation of cubic cobalt ferrite [33-36].

The prepared sample displays phonon modes $\left(\mathrm{A}_{1 \mathrm{~g}}+\mathrm{Eg}+\right.$ $3 \mathrm{~T}_{2 \mathrm{~g}}$ ) $[36,37]$. The Raman active modes respectively located at about 292, 460, 600 and $680 \mathrm{~cm}^{-1}$ are attributed to the phonon vibration modes Eg, $\mathrm{T}_{2 \mathrm{~g}}(2), \mathrm{A}_{1 \mathrm{~g}}(2)$ and $\mathrm{A}_{1 \mathrm{~g}}(1)$, which are well matching with the one of the spinel cobalt ferrite $\left(\mathrm{CoFe}_{2} \mathrm{O}_{4}\right)$ particles as reported in the literature [38].

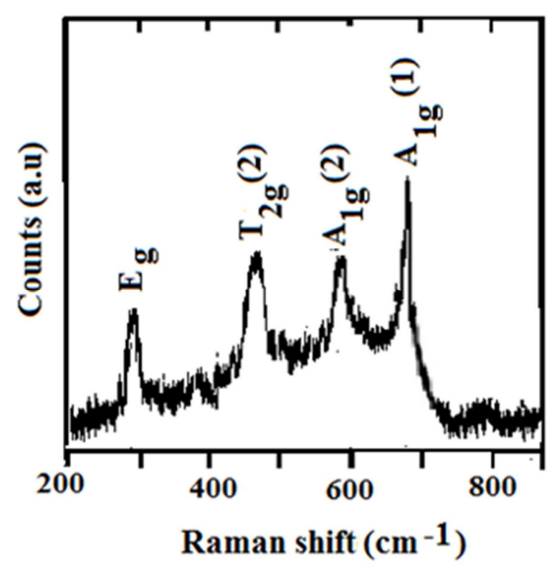

Figure 5. Raman spectra of $\mathrm{CoFe}_{2} \mathrm{O}_{4}$ (sample 5).

\section{6. $U$ V-Visible Measurements}

To gain information about the photocatalytic properties of the fabricated material, the optical measurements for different samples were recorded at room temperature using a UV-Visible absorption spectrophotometer as shown in Figure 6.

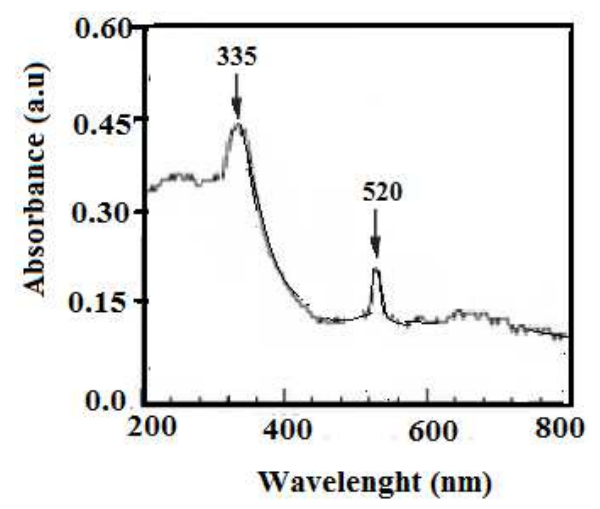

Figure 6. $U V$-Visible spectrum of $\mathrm{CoFe}_{2} \mathrm{O}_{4}$ (sample 5).

The spectrum exhibits two absorption bands at 335 and $520 \mathrm{~nm}$, where the first one could be assigned to the $\mathrm{O}^{2-}$ to $\mathrm{Co}^{2+}$ charge transfer process and the second band could be related to the $\mathrm{O}^{2-}$ to $\mathrm{Fe}^{3+}$ charge transfer [39]. These two characteristic bands are expected for the spinel made of $\mathrm{CoFe}_{2} \mathrm{O}_{4}$. From the spectrum, one can see that the fabricated samples exhibited an absorption from UV to visible light region, which demonstrates the possibility of these materials as catalysts under visible light.

\subsection{Magnetic Properties}

The synthetized spinel magnetic properties (sample of $30 \mathrm{kGy}$ gamma irradiated dose) at room temperature $(300 \mathrm{~K})$ is shown in figure 7 , where the magnetization $(\mathrm{M})$ as a function of the applied field $(\mathrm{H})$ is presented. 


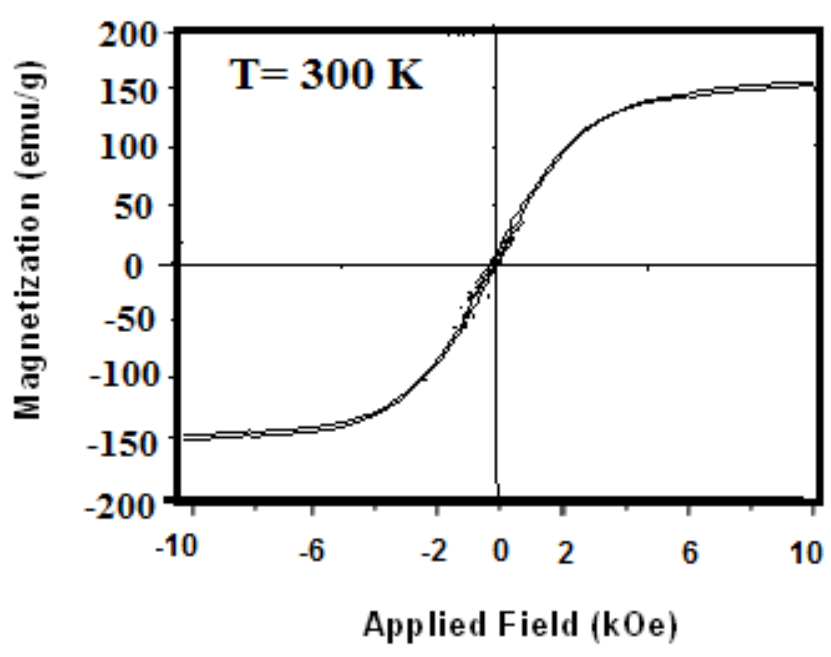

Figure 7. Magnetic properties of magnetite $\mathrm{CoFe}_{2} \mathrm{O}_{4}$ (sample 5).

The remanence of the fabricated spinel could be extrapolated to $150 \mathrm{emu}^{-1}$ at $10 \mathrm{kOe}$. The saturation magnetization is decreased, which is due mostly to the existence of surfactants on the surface of the spinel constituted of $\mathrm{CoFe}_{2} \mathrm{O}_{4}$. The measured lower coercivity and remanence are demonstrated that the spinel powders are made of superparamagnetic particles [40].

The superparamagnetic properties observed in the present investigation could be due to the special morphology of the prepared $\mathrm{CoFe}_{2} \mathrm{O}_{4}$ sample [41]. The gamma irradiation could be expected as a new route for preparing other metal oxides semiconductor.

\subsection{Radiolytic Formation of $\mathrm{CoFe}_{2} \mathrm{O}_{4}$ Mechanism}

To illustrate the production of $\mathrm{CoFe}_{2} \mathrm{O}_{4}$ under $\gamma$ - irradiation process, the following mechanisms could be suggested. The radiolysis of water leads to the production of free radicals such as: $\mathrm{e}^{-}$aq $, \mathrm{H} \cdot, \mathrm{OH} \cdot$ and $\mathrm{HO}_{2}$ or $\mathrm{O}_{2}^{-}$and molecular species such as $\mathrm{H}_{2}$ and $\mathrm{H}_{2} \mathrm{O}_{2}$. It is well known that, the hydrated electron, $\mathrm{e}^{-}$aq and hydrogen radical $\mathrm{H} \cdot$ are reducing species, and their standard electrode potentials at $25^{\circ} \mathrm{C}$ are respectively $-2.77 \mathrm{~V}$ and $-2.31 \mathrm{~V}$ while $\mathrm{OH} \cdot \mathrm{HO}_{2}, \mathrm{O}_{2}^{-}, \mathrm{H}_{2} \mathrm{O}_{2}$ are oxidizing species [42, 43].

$$
\mathrm{H}_{2} \mathrm{O} \rightarrow \mathrm{H}_{2}, \mathrm{H}_{2} \mathrm{O}_{2}, \mathrm{H} \cdot, \mathrm{OH} \cdot, \mathrm{e}^{-}, \mathrm{Hq}_{2} \mathrm{O}^{+}, \mathrm{H}_{2} \mathrm{O}^{*}, \mathrm{HO}_{2}
$$

The presence of $\mathrm{Co}^{2+}$ species $\left[\mathrm{Co}(\mathrm{OH})_{2}\right]$ and $\mathrm{Fe}^{2+}$ species $\left[\mathrm{Fe}(\mathrm{OH})_{2}\right]$ are required in the production of the spinel $\left(\mathrm{CoFe}_{2} \mathrm{O}_{4}\right)$ upon $\gamma$-irradiation, the $\mathrm{Fe}^{2+}$ adsorbed on $\left[\mathrm{Co}(\mathrm{OH})_{2}\right]$ will be rapidly oxidized to $\mathrm{FeOOH}$ by the oxidizing species from water radiolysis, such as ${ }^{\bullet} \mathrm{OH}$ and $\mathrm{H}_{2} \mathrm{O}_{2}$, through reactions (2) [44].

$$
\mathrm{Fe}^{2+}(\mathrm{sol})+{ }^{\bullet} \mathrm{OH} \rightarrow\left[\mathrm{Fe}(\mathrm{OH})_{3}\right] \rightarrow \mathrm{FeOOH}+\mathrm{H}_{2} \mathrm{O}
$$

In alkaline media, the reducing species $\mathrm{H} \cdot$ are converted to $\mathrm{e}^{-}$aq, which mainly play the major role in the course of reaction. The 2-propanol $\left.\left(\mathrm{CH}_{3}\right){ }_{2} \mathrm{CHOH}\right)$ scavenges both reducing and oxidizing species $(\mathrm{H} \cdot$ and $\mathrm{OH} \cdot)$ but under the given condtion, this alcohol is inert in reacting with the hydrated electron $\mathrm{e}^{-}$aq $[45]$. The hydrated electron $\mathrm{e}^{-}$aq reacts rapidly with the hydroxyl radical $\mathrm{OH}$, leading to the deprotonation of $\mathrm{OH} \cdot$ radical, which is converted to $\mathrm{O}^{-}$via the following reactions $[46,47]$ :

$$
\begin{aligned}
& \mathrm{H} \cdot+\mathrm{OH}^{-} \longrightarrow \mathrm{e}_{\mathrm{aq}}+\mathrm{H}_{2} \mathrm{O} \\
& \mathrm{H} \cdot+\left(\mathrm{CH}_{3}\right)_{2} \mathrm{CHOH} \longrightarrow \mathrm{H}_{2}+\left(\mathrm{CH}_{3}\right)_{2} \mathrm{C} \cdot \mathrm{OH} \\
& \mathrm{OH} \cdot+\left(\mathrm{CH}_{3}\right)_{2} \mathrm{CHOH} \longrightarrow \mathrm{H}_{2} \mathrm{O}+\left(\mathrm{CH}_{3}\right)_{2} \mathrm{C} \cdot \mathrm{OH} \\
& \mathrm{e}_{\mathrm{aq}}+\mathrm{OH}^{\cdot} \rightarrow \mathrm{OH}^{-}(\mathrm{E}=2.8 \mathrm{~V}) \\
& \mathrm{OH} \cdot+\mathrm{OH}^{-} \longrightarrow \mathrm{O}^{-}+\mathrm{H}_{2} \mathrm{O}(\mathrm{pK}=11.9)
\end{aligned}
$$

Then the reactions of $\mathrm{O}^{-}$species with the reducing species such $\mathrm{H} \cdot$ and $\mathrm{e}_{\text {aq }}^{-}$could produce of $\mathrm{OH}^{-}$according to the reactions:

$$
\begin{aligned}
& \mathrm{O}^{-}+\mathrm{e}_{\mathrm{aq}}^{-} 2 \mathrm{OH}^{-} \\
& \mathrm{O}^{-}+\mathrm{H}^{\cdot} \longrightarrow 2 \mathrm{OH}^{-}
\end{aligned}
$$

Under alkaline condition, the formation of the spinel cobalt ferrite, $\mathrm{CoFe}_{2} \mathrm{O}_{4}$ could be due to ferric oxyhydroxide, $\mathrm{FeO}(\mathrm{OH})$ reduction by hydrated electron (produced upon gamma irradiation), in the presence of stable cobalt ion, $\mathrm{Co}^{2+}$ species.

$$
\begin{gathered}
2 \mathrm{FeOOH}+\mathrm{Co}(\mathrm{OH})_{2}+2 \mathrm{e}_{\mathrm{aq}}^{-}+2 \mathrm{OH} \\
\rightarrow \mathrm{CoFe}_{2} \mathrm{O}_{4}+2 \mathrm{H}_{2} \mathrm{O}+2 \mathrm{OH}^{-}
\end{gathered}
$$

\section{Conclusion}

In the present investigation, gamma irradiation technology has been applied at room temperature, ambient pressure to prepare submicrometer $\mathrm{CoFe}_{2} \mathrm{O}_{4}$ particles. This spinel was fabricated without any kind of catalysts in water system. All characterization methods employed to get information about the structure, the composition, the purity and the nature of the prepared powder showed that, the fabricated sample was made of highly pure cobalt ferrite, which is exhibiting photo absorption from ultraviolet domain to visible light region, which implies the possibility for the prepared material to be efficiently used as photocatalytist under visible light.

The gamma irradiation could be expected as a new route for preparing other metal oxides semiconductor.

The degradation of textile dyes and the oxidation of alkenes (using the prepared material as catalyst) are under investigation and the results will be submitted soon.

\section{Acknowledgements}

To bring this work to completion, the authors would like to thank Dr Xin Lihui of Shanghai University, and Professor Dr Zhou Ruimin of Shanghai Applied Radiation Institute, Shanghai University, for the product characterization support. 


\section{References}

[1] P. Annie Vinosha, G. Immaculate Nancy Mary, K. Mahalakshmi, L. Ansel Mely, S. Jerome Das, Study on Cobalt Ferrite Nanoparticles Synthesized by Co-Precipitation Technique for Photo-Fenton Application, Mechanics, Materials Science \& Engineering, April 2017-ISSN 2412-5954.

[2] M. S.; Wang, D. H.; Yu, H. Q.; Tang, S. L.; Du, Y. W. Threedimensional phases-connectivity and strong magnetoelectric response of self-assembled feather-like $\mathrm{CoFe}_{2} \mathrm{O}_{4}-\mathrm{BaTiO}_{3}$ nanostructures. Chem. Phys. Lett. 2010, 496, 301-305.

[3] Rezlescu, N.; Doroftei, C.; Popa, P. D. Humidity-sensitive electrical resistivity of $\mathrm{MgFe} 2 \mathrm{O} 4$ and $\mathrm{Mg} 0.9 \mathrm{Sn} 0.1 \mathrm{Fe} 2 \mathrm{O} 4$ porous ceramics. Rom. J. Phys. 2007, 52, 353-360.

[4] Yavari, S., Mahmodi, N. M., Teymouri, P., Shahmoradi, B., Maleki, A. (2016). Cobalt ferrite nanoparticles: Preparation, characterization and anionic dye removal capability. Journal of the Taiwan institute of chemical engineers, 59, 320-329.

[5] Gan, L., Shang, S., Yuen, C. W. M., Jiang, S. X., Hu, E. (2015). Hydrothermal synthesis of magnetic $\mathrm{CoFe}_{2} \mathrm{O}_{4}$ /graphene nanocomposites with improved photocatalytic activity. Applied surface science, 351, 140-147.

[6] Singh, S., Khare, N. (2015). Magnetically separable, $\mathrm{CoFe}_{2} \mathrm{O}_{4}$ decorated $\mathrm{CdS}$ nanorods for enhanced visible light driven photocatalytic activity. Materials letters, 161, 64-67.

[7] Habibi, M. H., Parhizkar, J. (2015). Cobalt ferrite nanocomposite coated on glass by Doctor Blade method for photocatalytic degradation of an azo textile dye Reactive Red 4: XRD, FESEM and DRS investigations. Spectrochimica acta part A: Molecular and biomolecular spectroscopy, 150, 879885.

[8] Sun C, Lee JSH, Zhang M. Magnetic nanoparticles in MR imaging and drug delivery. Adv Drug Deliv Rev 2008; 60: 1252-65.

[9] Kim DH, Nikles DE, Johnson DT, Brazel CS. Heat generation of aqueously dispersed $\mathrm{CoFe}_{2} \mathrm{O}_{4}$ nanoparticles as heating agents for magnetically activated drug delivery and hyperthermia. J Magn Magn Mater 2008; 320: 2390-6.

[10] C. Suwanchawalit, V. Somjit, A facile hydrothermal synthesis of magnetic $\mathrm{CoFe}_{2} \mathrm{O}_{4}$ nanoparticles and photocatalytic performance, Digest Journal of Nanomaterials and Biostructures, Vol. 10, No. 2, April - June 2015, p. 705-713.

[11] T George, A T Sunny and T Varghese, Magnetic properties of cobalt ferrite nanoparticles synthesized by sol-gel method, 2015 IOP Conf. Ser.: Mater. Sci. Eng. 73012050.

[12] A. K Nikumbh, R. A Pawar, D. V Nighot, G. S Gugale, M. D Sangale, M. B Khanvilkar, A. V Nagawade, Structural, electrical, magnetic and dielectric properties of rare-earth substituted cobalt ferrites nanoparticles synthesized by the coprecipitation method, J. Magu. Magn. Mater, 2014 DOI: 10.1016/j.jmmm.2016.08.027.

[13] Diodati, S.; Nodari, L.; Natile, M. M.; Caneschi, A.; de Julián Fernández, C.; Hoffmann, C.; Kaskel, S.; Lieb, A.; Di Noto, V.; Mascotto, S. et al. Coprecipitation of oxalates: An easy and reproducible wet-chemistry synthesis route for transition metal ferrites. Eur. J. Inorg. Chem. 2014, 875-887.
[14] A. B Salunkhe, V. M Khot, M. R Phadatare, S. H Pawar, Combustion synthesis of cobalt ferrite nanoparticles-Influence of fuel to oxidizer ratio, J. Alloys comp 2012 DOI: 10.1016/j.jallcom.2011.10.094.

[15] Wang, M.; Ai, Z.; Zhang, L. Generalized preparation of porous nanocrystalline $\mathrm{ZnFe}_{2} \mathrm{O}_{4}$ superstructures from zinc ferrioxalate precursor and its superparamagnetic property. $J$. Phys. Chem. C 2008, 112, 13163-13170.

[16] Diodati, S.; Nodari, L.; Natile, M. M.; Russo, U.; Tondello, E.; Lutterotti, L.; Gross, S. Highly crystalline strontium ferrites $\mathrm{SrFeO}-\delta$ : An easy and effective wet-chemistry synthesis. Dalton Trans. 2012, 41, 5517-5525.

[17] J. C. Wren, ACS Symposium Series, American Chemical Society, Washington, DC, 2010, p. 271.

[18] J. M. Joseph, B.-S. Choi, P. A. Yakabusie and J. C. Wren, Radiat. Phys. Chem., 2008, 77, 1009.

[19] Ekoko Bakambo Gracien, Zhou ruimin, Xin LiHui, Lobo K. K, Ilinga $\mathrm{L}$, Effect of $\mathrm{pH}$ on the morphology of iron oxides synthesized under gamma irradiation, Journal of Radiaoanalytical and Nuclear Chemistry 270 (2), 2006, 473478.

[20] Zhang X, R. Zhou, W. Rao, Ekoko Bakambo Gracien, Y. Cheng, Influence of precipitor agents $\mathrm{NaOH}$ and $\mathrm{NH}_{4} \mathrm{OH}$ on the preparation of $\mathrm{Fe}_{2} \mathrm{O}_{3}$ nano-particles synthesized by electron beam irradiation, Journal of Radiaoanalytical and Nuclear Chemistry, 270 (2), 2006, 285-289.

[21] Ekoko Bakambo G., Joseph K. -K. Lobo, Omer M. Mvele, et al, Gamma Irradiation Inducing the Synthesis of Magnetic $\mathrm{Fe}_{3} \mathrm{O}_{4}$ Nanorod Particles in Alkaline Medium, International Journal of Materials Science and Applications, 3 (6), 2014, 339-343.

[22] Ekoko Bakambo Gracien, Zhou Ruimin, Xin LiHui, Adeleke O Francis Lobo K. K, "Synthesis of nanocrystalline zinc sulfide in a non-aqueous system by gamma irradiation", Journal of Radiaoanalytical and Nuclear Chemistry, 2005, 265, $1,3-6$.

[23] Jérémie L. Muswema, Gracien B. Ekoko, Joseph K. -K. Lobo, Omer M. Mvele, Hercule M. Kalele, Antoine K. Mbongo1 Gérard N. Mata, Gamma-radiation induced synthesis of spinel $\mathrm{Co}_{3} \mathrm{O}_{4}$ Nanoparticles, SN Applied Sciences (1: 2019)333 | https://doi.org/10.1007/s42452-019-0342-6

[24] Ekoko Bakambo Gracien, Muswema Lunguya Jeremie, Lobo Kanza-Kanza Joseph, Mvele Muamba Omer, Nzazi Kambamba Nicole, Nduku Mafwa Fabrice, Musengele Bilasi Denis, Ndonganzadi Tresor, Mukiatom Perdon, Mata Niasa Gerard. Nickel Oxide Nanocrystalline Fabricated Under Gamma Irradiation and Its Photocatalytic Investigation for Textile Azo Dye Degradation. Advances in Materials, Vol. 8, No. 3, 2019, pp. 112-119. doi: 10.11648/j.am.20190803.13.

[25] Ekoko Bakambo Gracien, Muswema Lunguya Jérémie, Lobo Kanza-Kanza Joseph1, Mvele Muamba Omer, Mbongo Kimpanza Antoine, Kalele Mulonda Hercule, Mata Niasa Gerard, Role of hydroxyl radical scavenger agents in preparing silver nanoparticles under $\gamma$-irradiation, SN Applied Sciences, 2019, 1: 961 | https://doi.org/10.1007/s42452-0190973-7

[26] S. Rohilla, S. Kumar, P. Aghamkar, S. Sunder, A. Agarwal, J. Magn. Magn. Mater. 323, 897 (2011). 
[27] Z. Gu, X. Xiang, G. Fan, F. Li, Facile synthesis and characterization of cobalt ferrite nanocrystals via a simple reduction-oxidation route, J. Phys. Chem. C112 (2008) 18459-18466.

[28] M. Vadivel, R. Ramesh Babu, K. Ramamurthi, M. Arivanandhan, Effect of PVP concentrations on the structural, morphological, dielectric and magnetic properties of $\mathrm{CoFe}_{2} \mathrm{O}_{4}$ magnetic nanoparticles, Nano-Struct. Nano-Objects 11 (2017) $112-123$.

[29] V. S. Kumbhar, A. D. Jagadale, N. M. Shinde, C. D. Lokhande, Chemical synthesis of spinel cobalt ferrite $\left(\mathrm{CoFe}_{2} \mathrm{O}_{4}\right)$ nano-flakes for supercapacitor application, Appl. Surf. Sci. 259 (2012) 39-43.

[30] N. Li, M. Zheng, X. Chang, G. Ji, H. Lu, L. Xue, L. Pan, J. Cao, J. Solid State Chem. 184, 953 (2011).

[31] L. Zhaoa, H. Zhanga, Y. Xinga, S. Songa, S. Yua, W. Shia, X. Guoa, J. Yanga, Y. Leia, F. Cao, Studies on the magnetism of cobalt ferrite nanocrystals synthesized by hydrothermal method, J. Solid State Chem. 181 (2008) 245-252.

[32] P. Vlazan, M. Stefanescu, P. Barvinschi, M. Stoia, Mater. Res. Bull. 47, 4119 (2012).

[33] Ayyappan, S.; Mahadevan, S.; Chandramohan, P.; Srinivasan, M. P.; Philip, J.; Raj, B. Influence of $\mathrm{Co}^{2+}$ ion concentration on the size, magnetic properties, and purity of $\mathrm{CoFe}_{2} \mathrm{O}_{4}$ spinel ferrite nanoparticles. J. Phys. Chem. C 2010, 114, 6334-6341.

[34] Chandramohan, P.; Srinivasan, M. P.; Velmurugan, S.; Narasimhan, S. V. Cation distribution and particle size effect on Raman spectrum of $\mathrm{CoFe}_{2} \mathrm{O}_{4}$. J. Solid State Chem. 2011, $184,89-96$.

[35] Nongjai, R.; Khan, S.; Asokan, K.; Ahmed, H.; Khan, I. Magnetic and electrical properties of Indoped cobalt ferrite nanoparticles. J. Appl. Phys. 2012, 112, 084321.
[36] Yamashita, O.; Ikeda, T. Effect of polishing stress on Raman spectra of the Mn-Zn ferrite. J. Appl. Phys. 2004, 95, 1743 1748.

[37] Varshney, D.; Verma, K.; Kumar, A. Structural and vibrational properties of $\mathrm{Zn}_{\mathrm{x}} \mathrm{Mn}_{1-\mathrm{x}} \mathrm{Fe}_{2} \mathrm{O}_{4}(\mathrm{x}=0.0,0.25,0.50$, $0.75,1.0)$ mixed ferrites. Mater. Chem. Phys. 2011, 131, 413419.

[38] P. Chandramohan, M. P. Srinivasan, S. Velmurugan, S. V. Narasimhan, Cation distribution and particle size effect on Raman spectrum of $\mathrm{CoFe}_{2} \mathrm{O}_{4}$, J. Solid State Chem. 184 (2011) 89-96.

[39] H. Guo, J. Chen, W. Weng, Q. Wang, S. Li, Chem. Eng. J. 239, 192 (2014).

[40] Chinnasamy, C. N.; Jeyadevan, B.; Shinoda, K.; Tohji, K.; Djayaprawira, D. J.; Takahashi, M.; Justin Joseyphus, R.; Narayanasamy, A. Appl. Phys. Lett. 2003, 83, 2862.

[41] Liu, B. H.; Ding, J.; Dong, Z. L.; Boothroyd, C. B.; Yin, J. H.; Yi, J. B. Phys. ReV. B 2006, 74, 184427.

[42] Buxton GV, Greenstock CL, Helman WP, Ross AB (1988). J Phys Chem Ref Data 17: 513-886.

[43] Spinks JWT, Woods RJ (1990), A Introduction to Radiation Chemistry. 3nd edition, Wiley-InterScience, New York, 285.

[44] Alrehaily LM, Joseph JM, Biesinger MC, Guzonas DA, Wren JC (2013). Phys Chem Chem Phys 15: 1014.

[45] P. Wardman, J. Phys. Chem. Ref. Data 18 (1989) 1637-1755.

[46] D. Madsen, C. L. Thomsen, J. Thogersen, S. R. Keiding, J. Chem. Phys. 113 (2000) 1126.

[47] B. Hickel, H. Corfitzen, K. Schested, J. Phys. Chem 100 (1996) 17186. 